\title{
MOVEMENT DISORDERS INDUCED BY PERIPHERAL TRAUMA
}

\author{
José Cláudio Marinho da Nóbrega', Cynthia Resende Campos', \\ João Carlos Papaterra Limongi', Manoel Jacobsen Teixeira ${ }^{1}$, Lin Tchia Yeng ${ }^{2}$
}

\begin{abstract}
Movement disorders induced by central nervous system trauma are well recognized. However, over the last few years, attention has been drawn to the role of peripherally induced movement disorders. We describe three patients presenting respectively dystonia, tremor and choreoathetosis associated with tremor and dystonia of the body parts previously exposed to traumatic injuries. Pathophysiological mechanisms underlying these phenomena are not entirely known, but functional changes in afferent neuronal input to the spinal cord and secondary affection of higher brain stem and subcortical centers are probably involved.
\end{abstract}

KEY WORDS: movement disorders, peripheral trauma, chorea.

\begin{abstract}
Distúrbios do movimento induzidos por traumatismo periférico
RESUMO - Distúrbios do movimento induzidos por traumatismo de sistema nervoso central já são conhecidos. Entretanto, nos últimos anos tem se dado maior atenção ao traumatismo periférico como indutor desses distúrbios. Relatamos três pacientes que apresentaram respectivamente distonia, tremor e coreoatetose com tremor e distonia em partes do corpo previamente traumatizadas. Os mecanismos fisiopatológicos que explicam esse fenômeno não são totalmente conhecidos, mas alterações nos impulsos neuronais aferentes para a medula interferindo secundariamente no funcionamento de estruturas corticais e subcorticais estão provavelmente envolvidas.
\end{abstract}

PALAVRAS-CHAVE: distúrbios do movimento, trauma periférico, coréia.

Movement disorders after traumatic events are usually related to central nervous system injuries, but sometimes may result from peripheral lesions. The association between peripheral trauma and movement disorders was first described by Gowers in 1888 who observed a patient with cervical dystonia after a local neck injury and noted that a patient with writer's cramp had previously sprained his thumb'. Despite those first descriptions, only recently attention has been drawn to peripheral trauma as a possible predisposing factor for movement disorders and growing scientific support for this concept has developed. Although temporal and topographic relationships have been closely established, including the concomitant occurrence of reflex sympathetic dystrophy in some cases, the pathophysiologic mechanisms underlying these phenomena are not well understood ${ }^{2-8}$.
We report three patients presenting a variety of movement disorders which developed few weeks after peripheral injuries nearby to the sites of the abnormal movements.

\section{CASES}

Patient 1. A 23-year-old man had been diagnosed with paranoid schizophrenia since 13 . He had been treated with haloperidol, periciazine and biperidene for approximately 12 years. Three years before the present evaluation he suffered a blunt trauma on his left shoulder and two weeks later he noticed involuntary contractions involving the muscles of the shoulder which progressed in severity over the following months. There was no family history of movement disorders. Neurological examination showed dystonic spasms and torsional movements involving the left trapezius and internal rotator of the left arm. Electrophysiological studies revealed the presence of dystonia in the proxi-

\footnotetext{
'Department of Neurology, Hospital das Clínicas, University of São Paulo, São Paulo SP, Brazil (USP); ${ }^{2}$ Department of Physical Medicine and Rehabilitation, Institute of Traumatology and Orthopedy, USP.

Received 26 June 2001, received in final form 25 September 2001. Accepted 8 October 2001.

Dr. João Carlos Papaterra Limongi - Departamento de Neurologia do Hospital das Clínicas da FMUSP - Av. Dr. Enéas de Carvalho Aguiar 255 - 05403-000 São Paulo SP - Brasil.E-mail: limongi@uol.com.br
} 
mal muscles of the left arm and in the left shoulder girdle. Anticholinergic drugs were of no benefit but botulinum toxin injections considerably relieved the abnormal contractions.

Patient 2. A 41-year-old man had a crushing trauma with partial loss of distal phalanges of the $2^{\text {nd }}, 3^{\text {rd }}$ and $4^{\text {th }}$ fingers of his left hand in 1998. He was submitted to surgical procedure and further resection of the distal phalanx of the $3^{\text {rd }}$ finger. Thirty days later, he developed a gross tremor in his left wrist which was more noticed when the arms were stretched and was partially relieved at rest. The tremor was worse during voluntary movements as closing and opening of his left hand but improved with other movements such as the index-to-nose test. He developed reflex sympathetic dystrophy with shocking pain, edema and vasomotor instability in his left hand. Electrophysiological studies suggested the presence of tremor of central origin precipitated by antigravitational postures. The tremor was not improved with propranolol but sympathetic dystrophy symptoms and tremor were transiently relieved after anesthetic block of the stellate ganglion.

Patient 3. A 56-year-old woman was diagnosed with breast cancer in 1998 and submitted to right mastectomy, chemotherapy and radiotherapy. She developed, as a result of radiotherapy, a right actinic brachial plexopathy. In 1999, after a fall, she presented a fracture of her right forearm and was treated with cast for immobilization. One month later the cast was removed and she developed choreoathetoid movements in her right hand, which were occasionally disturbed by postural and rest tremor. The neurological examination showed a brachial monoparesis, abolished deep tendon reflexes and superficial and deep hypoesthesia involving the right upper limb. During some voluntary movements, such as the index-to-nose test, she presented a dystonic posture. Electrophysiological studies revealed a chronic sensitive-motor lesion of the right brachial plexus.

\section{DISCUSSION}

Several types of involuntary movements resulting from peripheral trauma have been described. More commonly the predominant features are tremor, dystonia and parkinsonism but myoclonus, tics and hemifacial spasms may occasionally occur ${ }^{2-}$ 4,9-17. Although chorea has been rarely described after central nervous trauma, it has not, to our knowledge, been reported as a result of peripheral trauma. Therefore, our case 3 may represent the first report of chorea secondary to peripheral trauma.

In order to establish a consistent causal relationship between peripheral trauma and movement disorder, Jankovic ${ }^{2}$ proposed the following criteria which we also adopted: 1 . The injury should be se- vere enough to cause local symptoms persisting or requiring medical attention for at least two weeks after the trauma; 2 . The onset of involuntary movements must have occurred within one year after the trauma; 3 . The abnormal movements should be anatomically related to the site of the injury. Moreover, the causal relationship should be supported by the absence of other causes capable of producing the same symptoms, presence of reflex sympathetic dystrophy and poor response to conventional treatment $^{3}$. Regarding the latency for the onset of symptoms, some authors consider more extensive periods of time, ranging from two to eight years after the traumatic event $t^{9,10,18}$. When the onset of symptoms occurs within hours to days after the trauma, a causal relationship is easily accepted but this may not be the case when months or years have elapsed until the first symptoms become manifest. However, considering that pathologic changes such as aberrant reinnervation, ephatic transmission, remyelination or late inflammatory changes may cause the disturbance, more extensive latency periods should theoretically be accepted ${ }^{4}$. In a recent review, Jankovic $^{8}$ has described the clinical characteristics of peripherally induced dystonia, tremor, parkinsonism and other movement disorders providing a critical analysis of the scientific evidences supporting a relationship between peripheral trauma and movement disorders. Nonetheless this concept has been recently disputed and some controversy still remains ${ }^{18}$.

There are reasons to suggest that a direct mechanical effect upon the peripheral nervous system do not itself cause abnormal movements. Instead, a traumatic injury may exert an indirect effect precipitating or aggravating a pre-existing subclinical dysfunction ${ }^{2}$. Indeed, the low incidence of peripherally induced movement disorders compared to the large incidence of traumatic events in the general population suggests that some predisposing factor may be present before the trauma. Commonly associated factors are family history of essential tremor and/or dystonia, premature birth, perinatal hypoxia, delayed psychomotor development and use of neuroleptic drugs $^{2,11}$. Our first case (Patient 1) had used neuroleptics, patient 3 had been submitted to external radiotherapy, which could represent a previous traumatic factor and patient 2 did not present an identifiable predisposing factor.

Peripherally induced tremors is a known clinical condition $^{11-13,19}$ although the pathophysiological mechanisms involved are not entirely clear. In their 
series of 146 patients of peripherally induced movement disorders, Cardoso and Jankovic ${ }^{3}$ reported 28 patients with tremor, 11 of whom also had parkinsonism related to trauma. In most patients, the onset occurred within two months after the trauma. Possible predisposing factors were observed in 13 cases: nine had essential tremor or family history of essential tremor, dystonia or parkinsonism and in six there was a history of drug abuse, HIV infection, previous peripheral trauma, seizures, mental retardation and cauda equina lesion, recognized in one patient each. Because peripheral injuries are much more common than peripherally related movement disorders, these authors suggested that some preexisting central dysfunction may play a role in the pathogenesis of these movement disorders. Our patient developed tremor four weeks after the trauma and no predisposing factor was found.

Peripherally induced dystonia has been described $^{10-11,14,15,20}$ and, when associated with reflex sympathetic dystrophy, the term causalgia-dystonia syndrome has been applied ${ }^{20}$. Jankovic and van der Linden ${ }^{11}$ described 18 patients with dystonia at various sites (hand, forearm, foot, neck and jaw). Five of these patients had family history of dystonia or tremor, four had used antidopaminergic agents, two had previous essential tremor and one had sequelae of perinatal injury. Brin et al. ${ }^{14}$ in their series of 23 patients, described nine patients with familial history of dystonia. Shankla ${ }^{6}$ reported cases of oromandibular dystonia after tooth extraction, gingivectomy, root canal treatment, new denture, facial and jaw injuries. More than one third of those patients had one of the following predisposing factors: family history of movement disorders, previous use of neuroleptics, essential tremor or dystonia affecting other body sites. Schott ${ }^{10}$ described 10 patients presenting with dystonia induced by peripheral trauma, including two with features resembling dystonia musculorum deformans. The interval between the trauma and the onset of symptoms ranged from three days to eight years. According to this author, the rarity of dystonia musculorum deformans, with an estimated prevalence of 3 per million, suggests a causal relationship to the trauma instead of a fortuitous occurrence. Our patient with dystonia had been exposed to neuroleptics for many years but family history of movement disorders was negative. The latency for the onset of symptoms was 15 days and there was no pain.

Chorea have been rarely described as a result of trauma of central origin. Our patient may well rep- resent an even rarer presentation of choreoathetosis secondary to peripheral trauma. Two putative factors may have precipitated the abnormal movements: radiotherapy with actinic brachial plexopathy and a further forearm fracture. There were no other neurologic manifestations. Clinical follow-up and a normal brain computerized tomography excluded brain metastatic lesions as a possible cause for the abnormal movements. Moreover, the localized pattern of the symptoms and the presence of ipsilateral reflex sympathetic dystrophy further suggest a peripheral origin in this patient.

Reflex sympathetic dystrophy appears in up to $3 \%$ of all peripheral nerve injuries according to one series $^{5}$. The condition is usually progressive and is most often initiated by direct trauma to nerve, plexus or other soft tissue. Rarely, it may result from central nervous lesions such as stroke, tumor, cranial trauma, syrinx and spinal cord injury. Painful conditions associated with autonomic abnormalities have been referred to as Complex Regional Pain syndrome since $1994^{6}$. This condition is classified in type I (without peripherical and/or central neuropathy) and type II (with peripherical and/or central lesion). The clinical manifestations of reflex sympathetic dystrophy are intense burning local pain, commonly beginning at the distal part of the limb (even when the lesion is proximal) and often accompanied by hyperalgesia, allodynia, edema, hyperthermia or hypothermia, increased local hair growth and faster nail growth; in a second phase, signs of dystrophy appears such as hair loss, brittle nails, shiny, brawny and hyperhidrotic skin and bone atrophy. Months to years later, movement disorders may appear such as difficulty to initiate movements, weakness, tremor, dystonia (usually affecting flexor muscles) and hyperreflexia ${ }^{7}$. Some authors observed improvement of motor signs after sympathetic anesthetic block soon after the onset of motor symptoms suggesting that sympathetic disturbance may contribute to the appearance of abnormal movements ${ }^{7,19}$. It should be noted that our Patient 2 presented partial and transient motor improvement after anesthetic block of the cervicothoracic ganglion.

Several studies have shown that focal peripheral trauma may produce movement disorders as a result of signal changes of afferent impulses to the spinal cord which, in turn, could affect brainstem nuclei, basal ganglia and cortical activity ${ }^{4,10}$. Peripheral lesions can cause functional changes in second order neurons of the posterior horn of the spinal cord. In animals, after a few days after rizothomy, 
high frequency neuronal discharge was recorded in posterior horn (laminae V), thalamus and cerebral cortex during long periods ${ }^{21}$. In the light of the frequent association between peripherally induced movement disorders and pain, we suggest that the motor signs may be pathophysiologically analogous to the sensitive phenomena observed in phantom pain and causalgia. Likewise, peripheral deafferentation might induce changes in neural transmission and reorganization of local neural circuitry. This, in turn, would lead to increased evoked and spontaneous motor response, possibly mediated through gamma neurons overactivity, produced by either desinhibition, ectopic activation, ephatic transmission or collateral sprouting ${ }^{4,10}$.

In conclusion, although in some instances the association between trauma and movement disorders might be coincident, the close temporal and anatomical relationships frequently observed strongly suggest a cause and effect phenomenon. The notion that peripheral trauma can alter sensory input and induce central cortical and subcortical reorganization to generate abnormal movements has gained scientific support. Nonetheless, additional experimental studies are needed to further clarify the mechanisms possibly involved in abnormal movement production and the ways in which a peripheral lesion could affect basal ganglia activity. It should also be emphasized that a wide spectrum of movement abnormalities can result from a peripheral insult, such as tics and choreoathetosis, besides the more common forms represented by tremor and dystonia.

\section{REFERENCES}

1. Gowers WR. A manual of diseases of the nervous system. London: Churchill, 1888:659.

2. Jankovic J. Post-traumatic movement disorders: central and peripheral mechanisms. Neurology 1994;44:2006-2014.

3. Cardoso F, Jankovic J. Peripherally induced tremor and parkinsonism. Arch Neurol 1995;52:263-269.

4. Goetz CG, Pappert EJ. Trauma and movement disorders. Neurol Clin 1992;10:907-920.

5. Veldman PHJ, Reynen HM, Arntz IE, Goris RJA. Signs and symptoms of reflex sympathetic dystrophy: a prospective study of 829 patients. Lancet 1993;342:1012-1015.

6. Merskey H, Bogduk N. Complex regional pain syndromes. In Merskey $\mathrm{H}$, Bogduk N (eds). Classification of chronic pain: descriptions of chronic pain syndromes and definitions of pain terms. 2.Ed. Book News Inc, 1994;40-41.

7. Schwartzman RJ. Reflex sympathetic dystrophy. Curr Opn Neurol Neurosurg 1993; 6:531-536.

8. Jankovic J. Controversy: can peripheral trauma induce dystonia and other movement disorders? Yes! Mov Disord 2001;16:7-12.

9. Marsden CD, Obeso JA, Traub MM, et al. Muscle spasm associated with Sudeck's atrophy after the injury. Br Med J 1984;288:173-176.

10. Schott GD. The relationship of peripheral trauma and pain to dystonia. J Neurol Neurosurg Psychiatry 1985;48:698-701.

11. Jankovic J, Van Der Linden C. Dystonia and tremor induced peripheral trauma: predisposing factors. J Neurol Neurosurg Psychiatry 1988;51:1512-1519.

12. Cole JD, Illis LS, Sedgewick EM. Unilateral essential tremor after wrist immobilization: a case report. J Neurol Neurosurg Psychiatry 1989; 52:286-287

13. Herbaut AG, Souer M. Two other cases of unilateral essential tremor induced by peripheral trauma. J Neurol Neurosurg Psychiatry 1989; 52:1213.

14. Brin MP, Fanh S, Bressan SB, Burke RE. Dystonia precipitated by peripheral trauma. Neurology 1986;36 (Suppl 1):119.

15. Sankhla C, Lai EC, Jankovic J. Peripherally induced oromandibular dystonia. J Neurol Neurosurg Psychiatry 1998;65:722-728.

16. Factor SA, Molho ES. Adult-onset tics associated with peripheral injury. Mov. Disord. 1997;12:1052-1055.

17. Glocker FX, Deuschl G, Volk B, et al. Bilateral myoclonus of the trapezius muscles after distal lesion of an accessory nerve. Mov Disord 1996;11:571-575.

18. Weiner WJ. Controversy: can peripheral trauma induce dystonia? No! Mov Disord 2001;16:13-22.

19. Schwartzman RJ, Kerrigan J. The movement disorder of reflex sympathetic dystrophy. Neurology 1990;40:57-61.

20. Bhatia $\mathrm{KP}$, Bhatt $\mathrm{MH}$, Marsden $\mathrm{CD}$. The causalgia-dystonia syndrome. Brain 1993;116:843-851.

21. Nashold BS Jr. Introduction to Second International Symposium on Dorsal Root Entry Zone (DREZ) lesions. Appl Neurophysiol 1988;51:76-77. 